\title{
Conduits for cerebrovascular bypass and lessons learned from the cardiovascular experience
}

\author{
James K. LiU, M.D., Peter Kan, M.D., S. V. Karwande, M.D., \\ and William T. Couldwell, M.D., Ph.D. \\ Department of Neurosurgery, and Division of Cardiothoracic Surgery, University of Utah School of \\ Medicine, Salt Lake City, Utah
}

\begin{abstract}
Direct cerebral revascularization is an important procedure in the treatment of certain complex aneurysms and skull base tumors when acute sacrifice of the internal carotid artery is required. It likely remains an appropriate treatment in a small subgroup of patients with cerebral ischemia refractory to maximal medical management. Similar to cardiovascular surgery, the choice of a graft conduit is critical for a successful outcome. The standard conduits are interposition vein grafts (usually the greater saphenous vein), free arterial grafts (radial artery), and pedicled arterial grafts (superficial temporal artery). The goal of this review is to summarize the conduits commonly used in cerebral revascularization with emphasis on their patency rates and flow characteristics. Comparisons are made with similar data available in the cardiovascular literature.
\end{abstract}

KEY WORDS • bypass procedure • anastomosis • radial artery • saphenous vein graft

The theoretical basis of an extracranial-intracranial bypass to increase CBF for cerebroocclusive disease was first established by Fisher in $1951 .{ }^{13}$ The first successful STA-MCA bypass operations were reported by Yaşargil and colleagues in $1970 .{ }^{40}$ Since that pioneering work, cerebrovascular bypass has been undertaken in the management of complex skull base tumors, giant and fusiform aneurysms, and a select group of patients with medically refractory cerebral ischemia. The choice of the appropriate bypass graft depends on the size of the recipient vessel, availability of the donor vessel, availability of graft material, and the extent of blood flow augmentation required.

Low-flow grafts (15-25 ml/minute), such as an STA, are used if some collateral vessels are present and the need for blood flow augmentation is minimal or if only distal branches are available for anastomosis. High-flow grafts (70-140 $\mathrm{ml} /$ minute), such as an SVG, are used in cases in which acute ICA occlusion and replacement are required.$^{34}$ The RA allows for flow at a moderate volume of 40 to $70 \mathrm{ml} /$ minute.

\footnotetext{
Abbreviations used in this paper: $\mathrm{CBF}=$ cerebral blood flow; ICA = internal carotid artery; IMA = internal mammary artery; $\mathrm{MCA}=$ middle cerebral artery; $\mathrm{RA}=$ radial artery; $\mathrm{RAG}=\mathrm{RA}$ graft; STA = superficial temporal artery; SVG = saphenous vein graft.
}

\section{CEREBROVASCULAR BYPASS SURGERY Pedicled Arterial Grafts: STA}

Indications. Although the authors of the extracranialintracranial bypass study, ${ }^{12}$ published in 1985 , failed to demonstrate the efficacy of bypass over best medical therapy, it is recognized that the STA-MCA bypass likely remains an important technique in the treatment of a small subgroup of patients with cerebral ischemia related to hemodynamic compromise. It is also useful for direct revascularization in patients with moyamoya disease. ${ }^{20} \mathrm{In}$ addition, it is routinely undertaken in revascularization of distal vessels with planned sacrifice of the parent artery in the treatment of aneurysms that cannot be clipped. Lawton, et al. ${ }^{21}$ demonstrated successful trapping of giant supraclinoid aneurysms and subsequent revascularization by establishing an STA-MCA bypass. Such MCA aneurysms that cannot be clipped were trapped and revascularized using a double-barrel STA-MCA bypass. Revascularization in which a bypass is established from the STA to the posterior cerebral or the superior cerebellar artery has also been conducted in cases of complex basilar artery aneurysms. Vishteh, et al. ${ }^{39}$ performed STA-MCA bypasses in two patients with medically refractory symptomatic traumatic ICA dissection.

Graft Extraction. The STA trunk and both frontal and parietal branches are mapped out by using Doppler ultra- 
sonography. A skin incision is usually made along the course of the parietal branch of the STA by using the operative microscope to avoid injuring the artery. Alternatively, a V-shaped incision can be used if both frontal and parietal branches of the STA are planned to be donor vessels, as in the case of a double-barrel STA-MCA bypass. Minor side branches are coagulated and divided sharply. Approximately $1 \mathrm{~cm}$ of perivascular and adventitial tissue is sharply dissected from the distal end of the STA branches prior to performing the anastomosis. Both end-to-side or end-to-end anastomosis is possible.

Graft Patency. Graft patency can be achieved in more than $95 \%$ of cases with an STA-MCA bypass. ${ }^{16,25}$ According to the International Cooperative Study, the perioperative morbidity and mortality rates were 0.6 and $2.5 \%$, respectively. ${ }^{12}$ The advantage of the pedicled graft is that only one anastomosis is required.

\section{Radial Artery Grafts}

The RAG is a useful conduit for reconstruction of the ICA in cerebral revascularization. Long-term patency has been demonstrated in the surgical management of giant aneurysms of the cavernous and paraclinoid ICAs. ${ }^{17}$ The RA has a lumen that closely approximates that of the $\mathrm{M}_{2}$ segment and has the advantage of being a physiological conduit for arterial blood. ${ }^{32}$ Unlike venous grafts, it lacks valves and varices.

The RA is technically easier to harvest because it has a constant anatomical location and size and is more resistant to kinking than the saphenous vein. ${ }^{17}$ The diameter of the RA is $3.55 \pm 0.45 \mathrm{~mm}$, which is more compatible with the diameter of the $\mathrm{M}_{2}$ or $\mathrm{P}_{1}$ branches. ${ }^{19}$ In these cases, RAGs are preferable over high-flow SVGs because flow mismatch can lead to subsequent flow turbulence and graft thrombosis. Because of the valves and the venous endothelium in a vein graft, which may promote thrombosis with low-flow states, RAGs can better tolerate intermittent temporary occlusion in aneurysm dissection.

Graft Extraction. Before harvesting the RAG, an Allen test ${ }^{2}$ should be performed. Alternatively, a temporary clip can be placed on the RA intraoperatively while monitoring with a continuous pulse oximeter on the ipsilateral hand. If the oxygen saturation is normal, then the ulnar collateral vessels are sufficient for perfusing the hand.

The artery is exposed at the wrist and traced proximally in the forearm up to the brachial artery bifurcation. The branches of the RA are ligated and/or cauterized. The artery is left in situ until extraction, after which, a small, blunt needle is introduced into the RA. Heparinized saline solution is flushed into the RA until it visibly "pops" and distends. The artery is then plicated over the blunt needle, and the procedure is repeated. A similar process is also performed from the other end of the RA. After spasm of the vessel has been relieved in this manner, the vessel does not spasm again. ${ }^{32}$

Graft Patency. In 43 patients who underwent RAGinduced ICA reconstruction, Houkin, et al., ${ }^{17}$ reported an early patency rate of $95 \%$ at 3 weeks postoperatively. In the two cases of acute occlusion, one patient presented with cerebral infarction and permanent neurological deficits, whereas the other patient recovered completely within 1 month. Patients with patent grafts exhibited no ische- mic complications or hyperperfusion syndrome after surgery. Regarding long-term patency, there was no delayed occlusion in 20 patients with more than 5 years of follow up. Stenotic changes occurred in two patients; however, there was no sign of reduced CBF or neurological deficit.

Technical Considerations. Radial artery grafting is easier to perform because the vessel wall is thicker. The smooth arterial endothelium can support the slower flow through the vessel with less turbulence. Thus, they are easier to keep open compared with SVGs. In the early experience the major problem with the use of RAGs in cardiovascular bypass was the occurrence of spasm. Fortunately, it was subsequently eliminated after the introduction of the pressure distension technique. ${ }^{33}$

One theoretical disadvantage is that these are free arterial grafts. The RA is a muscular artery that relies on a vaso vasorum for its nutrition. Therefore, it was initially postulated that the free RAG would be associated with a higher risk of degenerative change in the arterial wall, producing acute atherosclerotic change and resulting in acute and chronic occlusion of the graft compared with venous conduits. This has been refuted by the data derived from both cardiovascular and cerebrovascular bypass procedures. In the cardiovascular literature, however, the longterm patency rate for pedicled arterial grafts, such as the IMA, is superior to that of RAGs. ${ }^{11}$ This may be explained by a significantly greater endothelial production of prostacyclin in the IMA, which counteracts the effects of thromboxane A2 in promoting platelet aggregation and thrombosis. ${ }^{4,7}$ Thus, RAGs, which produce less prostacyclin, have a higher propensity for spasm and rely on antispastic and antiplatelet drugs. ${ }^{6}$

The reasons for graft occlusion include problems with the proximal or distal anastomosis, poor endothelium of the donor or recipient arteries, kinking at the proximal or distal anastomotic sites, severe narrowing along the subcutaneous tunnel, significant size disparities between the graft and recipient vessels (resulting in severe turbulence), and spasm of the graft or the recipient artery. Postoperative spasm of the RAGs or the recipient artery can be treated by performing careful intraluminal angioplasty.

Coronary Bypass Data. The technique for RA grafting was first performed in coronary bypass surgery by Carpentier, et al., ${ }^{5}$ in 1973. It was thought that the RA was comparable in length and diameter to the IMA, the goldstandard conduit in coronary bypass. The RA is also accustomed to elevated systemic blood pressure, is easily harvested, possesses a thicker arterial wall making it easier to suture, and lacks the valves and varices characteristic of venous grafts. Early postoperative angiography revealed good patency rates. ${ }^{10}$ Despite initial promising results, however, there was a high rate of perioperative spasm and occlusion of the bypass conduit, and RAGs for coronary bypass fell out of favor. ${ }^{10,14}$ The development of calcium channel antagonists and improved harvesting techniques led to renewed interest in RAGs and restored their place in cardiovascular practice. ${ }^{1,18}$ With recent advances, the long-term patency rate associated with RAGs in patients undergoing myocardial revascularization has improved dramatically, with a 5-year patency rate of greater than $90 \% .{ }^{26}$ Although the IMA remains the preferred conduit for arterial myocardial revascularization, 
the RA is an excellent alternative conduit that offering good long-term clinical and angiographic results.

\section{Interposition SVG}

Saphenous vein grafts have been widely used in both coronary and peripheral vascular surgery. The saphenous vein is readily accessible from the lower leg and/or thigh and can be tailored to varying lengths. Greater SVG bypasses created between the extracranial and intracranial circulation were originally performed to provide acute high-volume collateral flow to the cerebral circulation in patients with impending cerebral infarction due to cerebroocclusive disease. ${ }^{22}$ More recently, SVGs have often been used in the treatment of giant aneurysms or skull base tumors when acute sacrifice of the ICA is necessary..$^{9,24,30,31,33,35-37}$

Graft Extraction. The thigh is abducted and externally rotated. An incision is made from the groin crease just medial to the femoral pulse toward the medial condyle of the femur. Once the vein is identified, it is followed cranially by the saphenofemoral junction. A 10 to $25-\mathrm{cm}$ length of the vessel is exposed, depending on the length of interposition graft needed. Papaverine $(3 \mathrm{mg} / \mathrm{ml})$ is injected into the adventitia. After the vein is harvested, the graft is flushed and irrigated with heparinized saline solution for a minimum period of time prior to anastomosis.

Graft Patency. In a review of 202 long SVGs for cerebrovascular bypass performed at the Mayo Clinic by Regli, et al.,28 14\% were occluded within 30 days of surgery. Of these, $62 \%$ were occluded within the 1 st day of surgery. Unfortunately, $72 \%$ of patients with early graft occlusion suffered neurological deterioration, including massive cerebral infarction with profound deficits. Late graft failures ( $>12$ months from the initial surgery) occurred in $8 \%$. The cumulative patency was $86 \%$ at 1 year, $82 \%$ at 5 years, and $73 \%$ at 13 years, with a mean annual graft failure rate of 1 to $1.5 \%$ after the 1 st year. In contrast to early occlusion, $80 \%$ of patients with a late graft occlusion remained asymptomatic. The cumulative 5-year survival rate was $78 \%$ in patients with a patent graft compared with $49 \%$ in those with an occluded graft.

Graft occlusion did not correlate with sex, cerebral vascular territory, primary cerebrovascular disease, or underlying vascular risk factors such as smoking, hypertension, coronary artery disease, or diabetes mellitus. Of the grafts in which blood flow was less than $50 \mathrm{ml} /$ minute, however, $36 \%$ became occluded compared with $13 \%$ in which the flow was between 50 and $200 \mathrm{ml} /$ minute $(\mathrm{p}<0.05) .^{28}$ Smaller-diameter veins of less than $6 \mathrm{~mm}$ had higher rates of occlusion. Vein grafts anastomosed to a larger trunk had a higher patency rate compared with those surgically attached to small branch of the posterior cerebral artery or MCA. These results are supported by Poiseuille's law; substantial flow is required to maintain graft patency. This phenomenon is also observed in SVG-established coronary bypass in which patency has been demonstrated to increase with flows rates greater than $40 \mathrm{ml} /$ minute and runoff vessel diameters greater than $1.5 \mathrm{~mm} .^{15,29}$

Technical Considerations. Early graft occlusion is due to thrombosis and fibrous intimal proliferation, probably as a result of early platelet deposition on the vein graft. This process is accelerated by turbulent blood flow and is most prominent at the site of the distal anastomosis. Late occlusion of the graft is mostly caused by the development of atherosclerosis in the vein grafts. Most of these occlusions are related to intraoperative technique. The surgeon should be mindful of endothelial damage of the vein graft, graft blood flow, and blood coagulability. ${ }^{38}$

Mechanical trauma inflicted on the vein may occur during harvesting and vein preparation or when sheer stress is placed on the vein transplanted to an arterial system. To reduce surgical manipulation, the vein is left in situ and covered with papaverine until transposition. To reduce the chance of acute thrombosis, patients are started on antiplatelet agents prior to surgery, undergo heparinization prior to temporary occlusion, and receive permanent antiplatelet therapy postoperatively.

The proximal and distal anastomoses should be reconstructed so that an adequate pressure head and minimal turbulence are provided. The shortest possible length of the vein graft, and end-to-end anastomosis at both ends of the graft are preferred to reduce turbulent flow. ${ }^{35} \mathrm{~A}$ major trunk, such as the supraclinoid ICA or MCA, should be the recipient vessel to ensure adequate runoff for the highflow SVG bypass.

Coronary Bypass Data. Traditionally, venous conduits, particularly the greater saphenous vein, are used as a conduit for coronary artery bypass. The 1-year patency rates for the aortocoronary greater SVGs are between 80 and $90 \% .^{23}$ In coronary bypass surgery, occlusion of vein grafts increases over time with thrombosis occurring in greater than $60 \%$ of aortocoronary grafts at 10 years postoperatively. ${ }^{3,8}$ Similar to cerebrovascular bypass experiences, early graft patency is thought to be related to operative technique, whereas late graft patency is related to the development of graft atherosclerosis. In prior studies, $50 \%$ of aortocoronary vein grafts had closed postoperatively at 10 years. Of those that remained patent, approximately $50 \%$ showed wall alterations consistent with vein graft atherosclerosis. There is a steep drop (10-20\%) in patency during the 1 st year after surgery. Thereafter the occlusion rate is 2 to $4 \%$ in the first 5 years, doubling to 4 to $8 \%$ annually after the 5 th year. ${ }^{27}$ In contrast, despite a similar early marked drop in the patency rate, the occlusion rate of SVGs in cerebral revascularization remained stable at 1 to $1.5 \%$ per year after the 1 st year. ${ }^{28}$

\section{CONCLUSIONS}

Choosing the appropriate conduit in bypass surgery is critical for successful cerebral revascularization. If the STA is unavailable or a higher-flow bypass is desired, interpositional conduits, such as the RA and saphenous vein, should be used. Meticulous technique in graft harvesting and microsurgical anastomosis is required for optimal graft patency.

\section{References}

1. Acar C, Jebara VA, Portoghese M, et al: Revival of the radial artery for coronary artery bypass grafting. Ann Thorac Surg 54:652-660, 1992

2. Allen EV: Thromboangiitis obliterans: methods of diagnosis of chronic occlusive arterial lesions distal to the wrist with illustrative cases. Am J Med Sci 178:237-244, 1929 
3. Bourassa MG, Fisher LD, Campeau L, et al: Long-term fate of bypass grafts: the Coronary Artery Surgery Study (CASS) and Montreal Heart Institute experiences. Circulation 72 (Suppl V):71-78, 1985

4. Bull DA, Reid BB, Albanil A, et al: Is the radial artery a preferred conduit for coronary artery bypass?, in American College of Surgeons (ed): Owen H. Wangensteen Surgical Forum: 83rd Annual Clinical Congress. Lawrence: Allen Press, Inc, 1997, pp 273-275

5. Carpentier A, Guermonprez JL, Deloche A, et al: The aortato-coronary radial artery bypass graft. A technique avoiding pathological changes in grafts. Ann Thorac Surg 16:111-121, 1973

6. Chardigny C, Jebara VA, Acar C, et al: Vasoreactivity of the radial artery. Comparison with the internal mammary and gastroepiploic arteries with implications for coronary artery surgery. Circulation 88:II115-II127, 1993

7. Chardigny CI, Van der Perre K, Simonet S, et al: Platelets and prostacyclin in arterial bypasses: implications for coronary artery surgery. Ann Thorac Surg 69:513-519, 2000

8. Chesebro JH, Fuster V, Elveback LR, et al: Effect of dipyridamole and aspirin on late vein-graft patency after coronary bypass operations. N Engl J Med 310:209-214, 1984

9. Couldwell WT, Zuback J, Onios E, et al: Giant petrous carotid aneurysm treated by submandibular carotid-saphenous vein bypass. Case report. J Neurosurg 94:806-810, 2001

10. Curtis JJ, Stoney WS, Alford WC Jr, et al: Intimal hyperplasia. A cause of radial artery aortocoronary bypass graft failure. Ann Thorac Surg 20:628-635, 1975

11. Dietl CA, Benoit CH: Radial artery graft for coronary revascularization. Ann Thorac Surg 60:102-110, 1995

12. EC/IC Bypass Study Group: Failure of extracranial-intracranial arterial bypass to reduce the risk of ischemic stroke. Results of an international randomized trial. The EC/IC Bypass Study Group. N Engl J Med 313:1191-1200, 1985

13. Fisher CM: Occlusion of the internal carotid artery. Arch Neurol Psychiatry 65:346-377, 1951

14. Fisk RL, Brooks CH, Callaghan JC, et al: Experience with the radial artery graft for coronary artery bypass. Ann Thorac Surg 21:513-518, 1976

15. Fuster V, Chesebro JJ: Aortocoronary artery vein-graft disease: experimental and clinical approach for the understanding of the role of platelets and platelet inhibitors. Circulation 72 (Suppl V):65-70, 1985

16. Gratzl O, Schmiedek P, Spetzler R, et al: Clinical experience with extra-intracranial arterial anastomosis in 65 cases. J Neurosurg 44:313-324, 1976

17. Houkin K, Kamiyama H, Kuroda S, et al: Long-term patency of radial artery graft bypass for reconstruction of the internal carotid artery. J Neurosurg 90:786-790, 1999

18. Iaco AL, Teodori G, Di Giammarco G, et al: Radial artery for myocardial revascularization: long-term clinical and angiographic results. Ann Thorac Surg 72:464-469, 2001

19. Kamiyama H: [Bypass with radial artery graft.] No Shinkei Geka 22:911-924, 1994 (Jpn)

20. Karasawa J, Kikuchi H, Furuse S, et al: Treatment of moyamoya disease with STA-MCA anastomosis. J Neurosurg 49: 679-688, 1978

21. Lawton MT, Hamilton MG, Morcos JJ, et al: Revascularization and aneurysm surgery: current techniques, indications, and outcome. Neurosurgery 38:83-94, 1996

22. Lougheed WM, Marshall BM, Hunter M, et al: Common carotid to intracranial internal carotid bypass venous graft. Technical note. J Neurosurg 34:114-118, 1971

23. Lytle BW, Loop FD, Cosgrove DM, et al: Long-term (5 to 12 years) serial studies of internal mammary artery and saphenous vein coronary bypass grafts. J Thorac Cardiovasc Surg 89: 248-258, 1985

24. Miyazaki S, Fukushima T, Fujimaki T: Resection of high-cervical paraganglioma with cervical-to-petrous internal carotid artery saphenous vein bypass. Report of two cases. J Neurosurg 73:141-146, 1990

25. Onesti ST, Solomon RA, Quest DO: Cerebral revascularization: a review. Neurosurgery 25:618-629, 1989

26. Possati G, Gaudino M, Alessandrini F, et al: Midterm clinical and angiographic results of radial artery grafts used for myocardial revascularization. J Thorac Cardiovasc Surg 116: 1015-1021, 1998

27. Reardon MJ, Conklin LD, Reardon PR, et al: Coronary artery bypass conduits: review of current status. J Cardiovasc Surg 38:201-209, 1997

28. Regli L, Piepgras DG, Hansen KK: Late patency of long saphenous vein bypass grafts to the anterior and posterior cerebral circulation. J Neurosurg 83:806-811, 1995

29. Roth JA, Cukingnan RA, Brown BG, et al: Factors influencing patency of saphenous vein grafts. Ann Thorac Surg 28: 176-183, 1979

30. Sekhar LN, Bucur SD, Bank WO, et al: Venous and arterial bypass grafts for difficult tumors, aneurysms, and occlusive vascular lesions: evolution of surgical treatment and improved graft results. Neurosurgery 44:1207-1224, 1999

31. Sekhar LN, Chandler JP, Alyono D: Saphenous vein graft reconstruction of an unclippable giant basilar artery aneurysm performed with the patient under deep hypothermic circulatory arrest: technical case report. Neurosurgery 42:667-673, 1998

32. Sekhar LN, Duff JM, Kalavakonda C, et al: Cerebral revascularization using radial artery grafts for the treatment of complex intracranial aneurysms: techniques and outcomes for 17 patients. Neurosurgery 49:646-659, 2001

33. Sekhar LN, Kalavakonda C: Cerebral revascularization for aneurysms and tumors. Neurosurgery 50:321-331, 2002

34. Sekhar LN, Kalavakonda C: Saphenous vein and radial artery grafts in the management of skull base tumors and aneurysms. Oper Tech Neurosurg 2:129-141, 1999

35. Sekhar LN, Sen CN, Jho HD: Saphenous vein graft bypass of the cavernous internal carotid artery. J Neurosurg 72:35-41, 1990

36. Sekhar LN, Wright DC, Olding M: Brain revascularization by saphenous vein and radial artery bypass grafting, in Sekhar LN, de Oliveira E (eds): Cranial Microsurgery: Approaches and Techniques. New York: Thieme Medical, 1999, pp 581-600

37. Spetzler RF, Fukushima T, Martin N, et al: Petrous carotidto-intradural carotid saphenous vein graft for intracavernous giant aneurysm, tumor, and occlusive cerebrovascular disease. J Neurosurg 73:496-501, 1990

38. Sundt TM III, Sundt TM Jr: Principles of preparation of vein bypass grafts to maximize patency. J Neurosurg 66:172-180, 1987

39. Vishteh AG, Marciano FF, David CA, et al: Long-term graft patency rates and clinical outcomes after revascularization for symptomatic traumatic internal carotid artery dissection. Neurosurgery 43:761-768, 1998

40. Yaşargil MG, Krayenbuhl HA, Jacobson JH Jr: Microneurosurgical arterial reconstruction. Surgery 67:221-233, 1970

Manuscript received January 15, 2003.

Accepted in final form February 7, 2003.

Address reprint requests to: William T. Couldwell, M.D., Ph.D., Department of Neurosurgery, University of Utah, 30 North 1900 East, Suite 3B409, Salt Lake City, Utah 84132. email: william.couldwell@hsc.utah.edu. 